\title{
Introducing Sport and Body Cultures in East and South East Asia
}

Friederike Trotier (Passau University, Germany) and Alan Bairner (Loughborough University, UK)

It is a pleasure to introduce this collection of essays which is the product of the scholarship of authors based in nine different countries - Australia, Germany, Hong Kong Special Administrative Region (SAR), Japan, Singapore, Taiwan, The Netherlands, the United Kingdom and the United States of America. Their collective efforts address themes relating to sport and body cultures in nine different countries - Hong Kong SAR, Indonesia, Japan, Macau SAR, Papua New Guinea (formerly Netherlands New Guinea), People’s Republic of China, Singapore, South Korea, and Taiwan.

Despite a widely-held, and not entirely erroneous, view that the cultures of east and south east Asia, influenced as they have long been by Confucian ideas, commonly favour the mind over the body or, at least, mental activity in preference to physical endeavour, this special issue sheds light of the wide range of diverse ways in which sport and body cultures feature in those parts of the world.

It is well known, for example, that since Tokyo hosted the Summer Olympics in 1964, numerous major events have been held in various cities in East Asia, most notably Seoul and Beijing which hosted the Olympics in the summers of 1998 and 2008 respectively. This long and ever-growing list of venues is completed at the time of writing by Taipei's hosting of the 2017 Universiade. The first two chapters in this collection discuss the reasons why Asian cities want to host sport mega events and how they do so.

In the opening chapter, Friederike Trotier examines the manner in which a city - in this particular case Palembang in Indonesia - can benefit as a consequence of hosting multi- 
national sport events. In this instance, the main benefit has been to improve the image of a city which, despite a long and relatively illustrious history, had acquired a reputation for being chaotic, dirty and backward, its inhabitants perceived as aggressive, treacherous and criminal. Trotier traces the transformation of Palembang into a city with a national and international reputation as a sports event destination.

Marcus Chu's chapter also addresses issues related to hosting major sports events. Specifically his focus is on the hosting of the East Asian Games by two Chinese administrative regions, Macau and Hong Kong, and one municipality, Tianjin. Although no doubt hosting the event was linked in each place, albeit to varying degrees, to a desire to enhance the image of the host, while Macau put on a relatively extravagant show and Hong Kong a more conservative one, Tianjin's hosting can be described as positively frugal. Chu argues that domestic concerns and influences help to explain the different approaches taken by the three hosts.

Hosting events is of course only one part of the story. East Asian sport leaders have made their mark on international organisations and countries, large and small, have increasingly made considerable investments in elite sport in the quest for trophies and medals. However, rather than focus on performance sport in the region which has been discussed at length elsewhere, the next two chapters examine what might be regarded as more idiosyncratic approaches to physical culture.

These chapters turn our attention towards body cultures more generally and away from sport per se even though sport, as commonly understood, remains an element in the second of these contributions. First, Yuchi Chang, Po-Hsiu Lin and Tsuneo Sogawa examine the growing interest in Taiwan in belly dancing. The women who participate in this activity, once regarded as foreign and, to a certain extent, exotic, do so for a variety of reasons, including 
the pursuit of weight-loss and body-shaping. However, as Chang et al demonstrate, the popularity of belly dancing in Taiwan also reflects ideas rooted in Chinese medicine and provides insights into the roles played not only by public health promotion but also by community universities.

Roger Casas writes about a very different population in his chapter as he analyses the cultivation of the body and sport practices among the Tai Lue Buddhist monks of Sipsong Panna in south west China. Casas describes the various ways in which forms of masculinity and of the male body are cultivated. In terms of sport, his focus is on the playing of basketball by the monastics. Casas argues that their enthusiasm for the sport should not be seen as a corruption of the monastic way of life but rather as a fundamental part of it. He calls for greater attention to be paid to the overall care for the body in the unfolding of monastic identities.

The next three chapters in this collection examine different organisations within which sport and other forms of physical activities are practised. Jelle Zondag outlines the role played by the scouting movement in Netherlands New Guinea from 1950 until 1962. Alongside the traditional aims of youth organisations to encourage, health, independence and confidence among young people, the Dutch colonialists also saw the movement as a vehicle for civilising, or arguably subordinating, local peoples and for unifying different tribes. As some Papuans subsequently came to realise, however, movements of this sort can also be used in more counter-hegemonic ways to promote self-government and independence.

Focusing more directly on sport, the next chapters focus on community sport clubs, in Singapore and South Korea respectively. Although most East Asian countries invest in elite sport, decisions about the value of sport are complicated by the presence of strong lobbies which favour grass roots participation and sport for all. Central to their vision of the social 
benefits of sport are community sport clubs. Wai Cheong Chew, Ho Jin Chung and Jung Woo Lee examine the role played by such clubs in the sport development of Singapore. Their story is generally positive with community clubs having played a significant role in ensuring relatively high participation rates. However, they also note that this role is diminishing with the social capital that clubs previously garnered now going largely to state-supported programmes.

In their examination of community sport clubs in South Korea, Sungwon Kim, Todd Seidler, Daniel Connaughton and John Spengler address a more specific concern, namely risk management practices or lack thereof in the clubs. They argue that risk management policies and practices are not conducted in a consistent manner in the clubs despite the fact that most managers are aware of a significant number of sport club-related injuries. This is a salutary reminder that, as people are encouraged to play sport and more generally to be physically active, there are always potential pitfalls which governing bodies and those charged with implementing their strategies ignore at their peril and to the risk of participants.

Last but by no means least, R. Kenji Tierney focuses on the bodies of sumo wrestlers in Japan, describing, and subjecting to social scientific analysis, the significance of the food that they eat. Tierney demonstrates how food, specifically sumo stew (chanko) creates not only the physical but also the social bodies of the wrestlers by connecting them with their fellow wrestlers. Thus, in this final essay in this collection, the concept of bodily culture assumes a corporeal form in what arguably one of the most basic of ways.

Friederike Trotier 
trotier@em.uni-frankfurt.de

Alan Bairner

Loughborough University, UK

A.E.S.Bairner@lboro.ac.uk 